\title{
ABUSO DE VULNERÁVEIS NO ÂMBITO FAMILIAR
}

\section{ARTIGO ORIGINAL}

MILHOMENS, Juan Carlos Moreira Cavalcante ${ }^{1}$

MACIEL, José Alves ${ }^{2}$

MILHOMENS, Juan Carlos Moreira Cavalcante. MACIEL, José Alves. Abuso de vulneráveis no âmbito familiar. Revista Científica Multidisciplinar Núcleo do Conhecimento. Ano 05, Ed. 03, Vol. 05, pp. 25-41. Março de 2020. ISSN: 2448-0959, Link de acesso: https://www.nucleodoconhecimento.com.br/lei/abuso-de-vulneraveis

\section{RESUMO}

O presente trabalho visa tratar do Abuso de Vulneráveis no Âmbito Familiar, através de uma pesquisa qualitativa com base bibliográfica, retratando o contexto da violência intrafamiliar, onde as principais vítimas são as mulheres, crianças e idosos, ocorrendo casos de violência física, psicológica, financeira, negligência e sexual, neste caso, tratando especificamente das crianças e adolescentes. Assim, por muito tempo, as crianças sofreram com culturas que não lhes viam como vulneráveis, sendo necessário o surgimento do Cristianismo para que as famílias consigam perceber as necessidades destas, e, deste modo, o Estado começa a intervir em proteção destes que atualmente são objetos de direitos e garantias. Os sintomas de abuso geralmente são psicológicos, como a agressividade, timidez ou choro, visto que ocorre com pessoas próximas, então, há uma grande dificuldade em encontrar vestígio, ainda,

1 Graduado (Bacharel) em Administração Pública pela UNITINS - Universidade Estadual do Tocantins, Graduado em Licenciatura em Informática pela UEG Universidade Estadual de Goiás e Acadêmico do 9º Período do Curso de Direito na UNIRG - Universidade de Gurupi.

2 Graduação em Direito; Especialização em Direito Processual Civil, Direito Penal e Direito Processual Penal. 
havendo a ligação emocional que faz com que as vítimas não consigam entender porque alguém que gostam tanto comete atos ruins, onde a dependência financeira $e$ a imaturidade biológica torna a denuncia ou a fuga mais dificultada. A Constituição Federal, os Códigos brasileiros e o Estatuto da Criança e do Adolescente moldam legislações que visam proteger estes de atos abusivos, entretanto, políticas preventivas ainda são necessárias junto a parcerias com outras instituições mais capazes de identificar vítimas.

Palavras-chave: Abusos Vulneráveis, intrafamiliar, sintomas, evidências.

\section{INTRODUÇÃO}

Todos os indivíduos, mesmo que pensantes, precisam passar por um processo de "humanização", uma formação histórica e social que faça com que este consiga encaixar-se nos valores, princípios e pensamentos do seu tempo e das pessoas que convive. A partir disto, este passa a ter um maior grau de consciência, tendo um amplo conhecimento, passando a compreender melhor a realidade em que está inserido.

A agressividade nem sempre está relacionada com a violência, as vezes é apenas uma resposta involuntária a um ato onde o indivíduo não tem consciência do que está fazendo, entretanto, a violência está sempre ligada diretamente com a agressividade, seja física, emocional, material ou psicológica. Assim, estas vêm passando a fazer parte do cotidiano da sociedade em números cada vez maiores, atingindo todos os locais e todas as idades, tornando-se um grande problema quando inserida no contexto escolar, dificultando o papel de formação e interação social que a instituição escolar possui.

É visível que a violência vem manifestando-se cada vez mais profundamente na sociedade brasileira, necessitando ter em mente que esta não se encontra associada somente à criminalidade, sendo consequência de diversos fatores ambientais, emocionais e comportamentais, podendo estar presente em qualquer local. Sendo assim, a mesma também se encontra dentro dos ambientes familiares, especialmente em relação a mulheres, idosos e crianças, havendo um grande avanço em termos de 
conscientização e busca de melhorias de suas realidades, entretanto, o número de casos de violência intrafamiliar ainda é crescente.

Apesar das várias políticas públicas dentro da gestão, onde toda uma legislação em proteção destes indivíduos foi criado, crianças, adolescentes e idosos possuem até seus próprios estatutos, há maior dificuldade encontra-se na identificação de casos e na reunião de provas, levando em consideração que o agressor é alguém tão próximo que os investigadores não desconfiariam e que a vítima possui certa dependência, e, desta forma, dificultar a denúncia, ou mesmo não compreende o que lhe acontece[3]. Então, apesar do Código Civil, Penal, Constituição Federal e Estatuto da Criança e do Adolescente visarem a proteção destes, a execução é dificultada.

A presente pesquisa visou retratar especificamente do abuso de vulneráveis intrafamiliar, utilizando uma pesquisa qualitativa com base bibliográfica, justificandose pela necessidade tanto dos estudantes da área do Direito quanto da sociedade em geral identificarem onde vem ocorrendo falhas e compreenderem este processo tão complexo de violência intrafamiliar, visando novas metodologias para o estabelecimentos de políticas preventivas, identificação e proteção destas crianças e adolescentes.

Respondendo a seguinte problemática: Como se dá o abuso intrafamiliar e como as legislações vem conseguindo alterar tal realidade? Objetivando retratar a violência familiar dentro de um contexto geral para a apresentação do abuso de vulneráveis por parentes, determinando as legislações que moldaram mudanças neste campo e determinando metodologias mais facilitadas de prevenção.

\section{VIOLÊNCIA INTRAFAMILIAR}

A violência permanece presente em todo o cotidiano atual, contudo, esta realidade provém de uma cultura que idolatra os atos violentos a muitos séculos, onde as guerras e as torturas eram vistas como atos de coragem, e a comunicação pacifica e acordos foram colocados de lado, como a sociedade romana que possuía sua economia baseada nas guerras e nas conquistas, possuindo escravos e vendendo- 
os, e quando houve uma mudança nesta perspectiva o Estado entrou em uma grande crise levando anos para recuperar-se.

Ainda, diante de tantas relações envolvendo o poder, especialmente após o entendimento a respeito da razão, onde os homens passaram a ver-se como capazes de dominar a natureza e uns aos outros, estabelecendo um "contrato social" que moldasse a sociedade em prol da liberdade dos indivíduos, contudo, com o desenvolvimento do comércio e do capitalismo, houve uma ascensão de burguês que conseguiam dominar tanto economicamente quanto em relação as políticas públicas, havendo uma real desenvolvimento em prol das classes menos favorecidas apenas com o uso da força.

Neste sentido, tal fenômeno é muito complexo, e encontra-se inserida em todos os campos sociais, mesmo que imperceptível, sendo o resultado de todas estas diferentes relações humanas que só conseguiam alterar-se, por muito tempo, através de atos violentos, onde o medo contava de maneira importante com a quantidade de poder pelo líder.

No Brasil, a terceira causa de mais mortes é a violência, demonstrando o quanto a mesma ainda é um fenômeno atual e recorrente, moldando a vida social de uma população que permanece com medo de tornar-se uma vítima. Dentro de tal contexto, há a violência intrafamiliar, esta tornou-se um problema de saúde pública demonstrando o quanto os casos vêm tendo seus números crescentes ao longo dos anos, ocorrendo quando há laços sanguíneos entre os indivíduos, marcando por ação ou omissão.

Representa todo ato ou omissão praticado por pais, parentes ou responsáveis

contra crianças e adolescentes que - sendo capaz de causar da no físico, sexual e/ou psicológico à vítima - implica, de um lado, uma transgressão do poder/dever de proteção do adulto e, de outro, uma coisificação da infância, isto é, uma negação do direito que crianças e adolescentes têm 
de ser tratados como sujeitos e pessoas em condição peculiar de desenvolvimento.[4]

É indispensável a compreensão de que os atos violentos não dependem das relações econômicas ou educativas, elas estão inseridas no modo de vida brasileiro de forma que todos os âmbitos destas permanecem crendo nestes atos como uma iniciativa normal, sendo um problema público onde o Estado necessita tomar partido.

Há uma grande necessidade de suporte para estes indivíduos, especialmente, em relação a prevenção, visto que é a maneira mais eficaz de evitar estes casos, como forma de impedir estes casos a Constituição Federal[5] trouxe seu artigo 226, parágrafo 8ㅜㅡ, atuando em defesa de tais vítimas, entretanto, ainda há altas taxas destes casos, sendo mister novas políticas públicas sociais.

O sistema de saúde tornou-se o mais capaz de identificar as vítimas de violência intrafamiliar, levando em consideração que estas não costumam denunciar, ou em caso de menores, estes não conseguem fazer a denúncia, assim, com a recorrência de atendimentos, ou mesmo exames, há a comprovação de machucados que podem denunciar estes casos, sendo fundamental uma parceria com os quadros de atendimento familiar dentro do Sistema Único de Saúde, Guerra define a violência intrafamiliar:

A prevenção primária é a maneira mais econômica, eficaz e abrangente para se evitar a violência contra a criança. Através de prevenção primária atua-se para modificar condutas e formar novas culturas, sensibilizando e mobilizando a sociedade[6].

A violência intrafamiliar pode ocorrer de várias formas e com graus alternados, onde o grupo com maior vulnerabilidade é formado por crianças, mulheres e idosos, podendo ocorrer negligência, violência física, psicológica, financeira e moral. Assim, as consequências decorrentes destes atos são enormes, onde há o desenvolvimento de problemas sociais, havendo uma dificuldade de socialização, emocionais e 
psicológicos, em alguns casos, levando estas vítimas, sem o tratamento correto, a cometer suicídio.

Segundo Azevedo[7], a violência intrafamiliar vem sendo estudada a cerca de 4 décadas, no Brasil, onde ocorre com pessoas de laços sanguíneos ou mesmo responsáveis legais, tanto pela magnitude quanto pelas repercussões do problema. Então, Ribeiro[8], dispõe que dada a explanação da magnitude destes acontecimentos que houve a passagem da violência sexual com um caráter endêmico, tornando-se um problema de saúde pública a ser enfrentado pela sociedade como um todo.

A negligência corresponde ao não atendimento de necessidades físicas e cognitivas básicas, isso pode ocorrer durante um período curto ou longo de tempo, comprometendo o desenvolvimento das crianças e adolescentes, sendo visto como um ato de violência para com estes, determinando a violência sexual como:

Qualquer ato ou contato sexual de adultos com crianças ou adolescente, com ou sem uso de força ou violência, que pode ocorrer num único ou em vários episódios, de curta ou longa duração, e que resulta em danos par a saúde, a sobrevivência ou dignidade da vítima[9].

De acordo com Minayo[10], há pesquisas que estimam que cerca de $20 \%$ das crianças e adolescentes sejam, hoje, vítimas de atos de violência e abuso, contudo, ainda faltam pesquisas nacionais que consigam estimar a extensão da violência intrafamiliar praticada contra indivíduos que possuem de zero a dezoito anos.

Azevedo e Guerra[11] consideram que este tipo de violência, atingindo crianças e adolescentes, cometida pelos próprios pais ou outros parentes, demonstra uma transgressão por parte dos adultos, estes além de não cumprirem o dever de proteção, são os próprios agentes da violência.

Durante muito tempo, as mulheres foram excluídas da historiografia, e isto formou um contexto de exclusão e estereotipo das mulheres, onde as mesmas são vistas como inferiores e necessitam dessa dominação por parte dos pais, formando uma cultura 
que disseminou a violência contra a mulher, onde no Brasil colônia os maridos corrigirem suas mulheres com o uso de chibatas era visto como um ato positivo.

Desta maneira, a violência contra a mulher ainda é bastante presente dentro da sociedade brasileira, havendo atos repetitivos que vão, gradativamente, agravandose, através de coerção, cerceamento, humilhação, desqualificação, desqualificação, ameaças e agressões físicas e psicológicas duradouras.

As mulheres nas últimas décadas marcaram com avanços e retrocessos, onde a Lei Maria da Penha foi um marco na história da proteção desta parcela social, contudo, ainda há uma grande fragilidade dentro dos aparatos legais, especialmente, pela dificuldade de haver denuncias por parte das vítimas que não se sentem protegidas suficiente pelo poder público.

Esta violência contra a mulher é movida na maior parte dos casos pelo ciúme, onde há um grande abuso de poder por parte dos homens que são considerados os provedores da casa e, por isto, necessitam permanecer "comandando", havendo a permanência desta violência de gênero, uma característica cultural que vem passando hereditariamente, onde ainda há uma grande aceitação destes atos.

Neste contexto, mulheres nem sempre conseguem apoio no local em que estão inseridos, seja por parte das famílias que veem estes atos de uma maneira diferente, ou mesmo em relação aos seus filhos que permanecem sem compreender os atos e buscando uma boa relação entre seus pais.

Os idosos estão inseridos em uma das categorias que mais comete suicídio, isto ocorre porque os mesmos creem que são inúteis para quaisquer atos, sofrendo ainda, por parte, principalmente, dos filhos e netos, de violência, seja ela física, psicológica e financeira, ainda, havendo a negligência, onde estes ocorrem por ação ou omissão, onde muitos encontram-se abandonados em asilos.

Santos et al.[12] afirma que todos os indivíduos que sofrem com a violência intrafamiliar possuem consequências muito especificas, ultrapassando o caráter 
particular, entretanto, há uma grande neutralização, por parte da sociedade, destes atos, realizando um tipo de ocultamento.

Portanto, a violência intrafamiliar é uma realidade que se demonstra muito presente ainda dentro da sociedade, atingindo todos os indivíduos que são considerados vulneráveis, e, mesmo havendo políticas públicas que visem impedir e punir estes acontecimentos, ainda é fundamental que o Estado consiga ver tais casos de maneira maior, conscientizar indivíduos e atuar com mais afinco, proporcionando mais eficácia as leis através de projetos e iniciativas.

\section{ABUSO DE VULNERÁVEIS NO ÂMBITO FAMILIAR}

$\mathrm{Na}$ antiguidade as crianças eram vistas como pequenos adultos, vestiam-se de maneira igual e possuíam os mesmos comportamentos, sendo tratadas da mesma forma, os casos de negligência e abandono eram altos, onde os indivíduos não possuíam esta ligação que Ihes dizia serem responsáveis por seus filhos. Com o passar dos anos, e o surgimento da Igreja Católica, a prática de matar bebes foi dado como casos de bruxaria, a linhagem sanguínea passou a ser vista como algo importante, e, após os casamentos, as famílias assumiram a responsabilidade pela criação destes, necessitando oferecer comida e educação, regulando a forma com que estes veriam seus filhos, Azambuja demonstra tal realidade:

$\mathrm{Na}$ história do Brasil, vem de longe o desrespeito à criança. Antes mesmo do descobrimento oficial, já são encontrados registros de desproteção. Na condição de órfãos do Rei, como grumetes ou pajens, as crianças portuguesas eram enviadas nas embarcações, para casarem com os súditos da Coroa. Poucas mulheres vinham nas viagens e as crianças eram "obrigadas a aceitar abusos sexuais de marujos rudes e violentos" (RAMOS, 1999, p. 19). Por ocasião dos naufrágios, comuns na época, "eram deixadas de lado pelos adultos, e entregues à fúria do mar” (DAY et al., 2003, p. 11).[13] 
Assim, aos poucos surge o conceito de criança e as pessoas começam a compreender que estes indivíduos precisam de cuidados especiais, havendo uma disseminação da cultura de proteção, surgindo, posteriormente, leis que as regulam, onde o Estado torna-se responsável por tutelar os interesses individuais e coletivos, oferecendo liberdade, desde que não transgridam os limites da naturalidade humana.

O Estatuto da Criança e do Adolescente (ECA) foi um marco na legislação, trazendo direitos e garantias para as crianças, de zero até doze anos incompletos, e de adolescentes, de doze a dezoito anos incompletos, Ishida[14] cita: "[...] além dos direitos fundamentais da pessoa humana, gozam a criança e o adolescente do direito subjetivo de desenvolvimento físico, mental, moral, espiritual e social, preservando-se sua liberdade e dignidade".

Guerra[15], explicita a negligência como uma omissão nas capacidades de prover as necessidades físicas e emocionais de uma criança ou adolescente, quando os pais, ou outros responsáveis, falham em termos de alimentar, vestir, adequadamente seus filhos, e quando está falha não é dependente de uma condição de vida além de seu controle.

Desta maneira, mesmo que atualmente estas sejam mais protegidas, há uma grande cultura que explicita a falta de proteção a estes indivíduos que ocorre a muitos séculos, onde, nestas épocas, marca-se a existência de práticas que brincam com o sexo da criança, estando tal questão presente em várias culturas diferentes, demonstrando como os adultos viam as mesmas.

O abuso intrafamiliar possui um número crescente de casos, onde o estupro e a corrupção de menores mostra-se como os casos que mais aparecem, estando, anteriormente, entre os crimes contra a liberdade sexual, mas, com a Lei 12.015 de 2009, passou a Alencar crimes hediondos e contra a Dignidade sexual recebendo mais punições, ainda, havendo questões relacionadas a negligencia e abusos físicos e psicológicos. 
A violência intrafamiliar contra a criança vem ocupando grande espaço nas análises contemporâneas sobre a violência, mas não por ser um fenômeno recente. Os maus tratos, os abusos físicos e sexuais sempre estiveram presentes na esfera familiar, como demonstra a história. No entanto, eram vistos como o exercício, pelos pais, de seus direitos sobre os filhos, assegurados pelas leis, pelos costumes e pelos princípios religiosos[16].

Nem sempre há a percepção de que estes atos vêm ocorrendo, especialmente, se eles se iniciam quando a criança é muito nova, esta acaba acostumando-se com tais atos, visto que quem os prática é uma pessoa próxima, a qual ela conhece e confia. Assim, os garotos, em casos de abuso sexual principalmente, podem apresentar vergonha sobre o que Ihes vem ocorrendo, e culpa por serem vítimas, considerando que são homens e há a disseminação de uma cultura machista que demonstra que estes precisam enfrentar estes atos e mostrarem-se mais fortes, causando mais danos psicológicos, onde os casos de denuncia ocorrem em menor número.

Atualmente, consegue-se compreender certos sintomas que podem ser atribuídos ao abuso intrafamiliar, como a agressividade, timidez, ou choro constante, havendo uma falta de preparo para o diagnóstico da depressão infantil, a qual é capaz de trazer as crianças irritabilidade e falta de desenvolvimento em sala de aula, com sintomas diferentes da depressão adulta, pode ser atribuída a apenas uma rebeldia comum pela idade. Por isto, torna-se muito importante haver uma ligação entre as Políticas Públicas que visam prevenir e punir tais casos e dos atendimentos mais específicos do Sistema Único de Saúde, considerando que com o acesso ao histórico médico e o entendimento a respeito de todo o quadro, seja ele psicológico ou físico, consegue-se uma maior atenção a respeito dos sintomas e a descoberta de abusos que vem ocorrendo, tornando estas políticas mais eficazes.

Neste contexto, é preciso expor o ato sexual entre parentes, o incesto, como uma prática antiga, apesar do Código Civil, a partir do Art. 1.521, proibir os casamentos entre familiares diretos. Mas, estes atos só podem ser considerados como incesto quando os dois indivíduos são maiores de idade e o fazem de livre e espontânea 
vontade, diferente da exploração sexual da criança e do adolescente, levando em consideração que estas, por estarem tão próximas de seus familiares e compreenderem suas falas como tão importantes, podem nem sempre utilizar da força, apenas coagindo com o uso de chantagens psicológicas ou demonstrando haver uma "ligação" que permite estas ações, assim, as vítimas nem sempre conseguem entender porque estas pessoas que gostam tanto tomam este tipo de iniciativas.

O abuso sexual sempre constitui uma forma de violência (física ou psicológica), na qual o abusador se aproveita de sua superioridade (física ou psicológica). Esse tipo de ato tem como consequência um atraso ou prejuízo no desenvolvimento ou estruturação da personalidade. $\mathrm{Na}$ maior parte das vezes gera trauma psíquico, geralmente prolongado, e o contato físico tem como único objetivo a satisfação sexual do abusador[17].

Cohen[18], demonstra que a história humana está repleta de casos de incestos, sendo uma prática permitida pelos imperadores onde eram vistos como a representação de Deus na terra. Então, estes poderiam realizar tais atos devido a sua origem divina, possuindo o sangue puro, no Egito a união entre irmão era vista como uma homenagem aos deuses Isís e Osíris.

A violência pode ser descrita como a utilização da força para certa coação, nestes casos pode ocorrer de maneira física, psicológica, negligência ou sexual, onde há tanto uma dificuldade em relação a descoberta como a união de evidências comprobatórias, onde os cuidadores ficam fora de suspeita devido a sua ligação tão próxima com as vítimas.

Chauí[19] descreve a violência é uma ação que deixa de tratar o outro como um ser humano, mas como objeto, ocorrendo com o surgimento de uma diferença que passa a ser transformada e tratada como uma desigualdade. Desta forma, a Secretária das políticas de saúde descreve esta sendo toda ação ou omissão que prejudique o bemestar, a integridade física, psicológica ou a liberdade e o direito ao pleno 
desenvolvimento de outro membro familiar, podendo ser cometida dentro ou fora de casa, incluindo por pessoas que passam a cumprir uma função parental, mesmo sem laços consanguíneos, mas que haja uma relação de poder sobre outra.

Os pais tem um papel fundamental dentro das casas, são os responsáveis por comandar a família, tanto financeiramente quanto em relação as regras, culturas e crenças, havendo, por parte das crianças e dos adolescentes, grande dependência, levando consideração que os mesmos não podem trabalhar durante o período que estão estudando, não conseguindo sustentar-se sozinhos, e, durante a infância, não possuindo maturidade biológica e emocional para se cuidarem sozinhos.

Neste contexto, Azevedo[20] dispõe a respeito da relação entre vítima e agressor: "[...] a vítima tem restringida não apenas sua atividade de ação e de reação como também sua palavra é cassada e passa a viver sob o signo do medo: medo da coação, medo da revelação".

Em outros casos, como informa Furniss[21], há um forte apego das vítimas em relação aos agressores, onde a atenção abusiva que recebe aparenta para ela o cuidado parental mais importante, ou, inclusive, o único que recebe. Estas crianças podem não querer desistir de tais relacionamentos, apesar de todo o prejuízo trazido, sentindo como algo positivo visto que não tem contato com outros tipos de relação, como pode ser identificado em famílias com um único progenitor.

A falta de interferência ou denúncia dos acontecimentos faz com que a violência continue presente dentro de um circulo silencioso que piora gradativamente devido o entendimento, por parte do agressor, de que não haverá denúncias, entre os casos atuais onde uma denúncia tornou capaz a saída de várias vítimas para a fala e a expressão do que Ihes aconteceu, ao contrário isto pode representar a passagem para outras gerações de tais relações abusivas entre as famílias.

Ainda, é evidente que quando há um maior nível conjugal há um menor número de denuncias por parte da mãe, isto mostra-se claro em uma realidade onde esta pode achar apoiar tais atitudes ou demonstrar neutralidade, ou mesmo em que esta 
dependa de maneira financeira do marido e ainda haja uma grande ligação imposta pelo medo, de tal forma que esta não consegue ir embora e não possui outros indivíduos que lhes ofereçam apoio, permanecendo calada.

[...] da imaturidade e insegurança da vítima, colocando em dúvida a importância que tem a sua família, diminuindo ainda mais seu amor próprio, ao demonstrar que qualquer queixa por parte dela não teria valor ou crédito. O abuso é progressivo; quanto mais medo, aversão ou resistência pela vítima, maior o prazer do agressor, maior a violência[22].

Nem sempre o abuso sexual ocorre através de atos físicos diretos, podendo ocorrer apenas de maneira verbal, onde o individuo é levado a falar coisas que agradem o outro ou mesmo ouvir, através do olhar, onde a vítima é observada enquanto toma banho ou dorme, nem sempre sabendo do que vem ocorrendo, havendo atos exibicionistas, no qual o agressor mostra suas partes sexuais ou faz com que a vítima assista a alguma cena, e através de filmagens que ligam o abuso sexual a prática da pedofilia, fazendo com que outros possam ter acesso a tais imagens.

Nas palavras de Pinto Junior et al.[23], a violência sexual pode ser associada as experiências do agressor, normalmente de abusos sexuais vivenciados em sua infância, principalmente, no ambiente familiar. Então, na maioria dos casos os conflitos não elaborados e não resolvidos de maneira adequada podem fazer com que o sujeito reviva este drama, tornando-se futuramente um agressor ou um abusador infantil. Por isto, torna-se tão importante as políticas de prevenção e tratamento correto destes casos, impedindo que a problemática volte a se repetir, onde Eisenstein consegue definir o abuso:

O abuso pode se manifestar através de maus tratos, exploração sexual ou comercial, molestamento, exibicionismos, manipulação, masturbação, estupro, contatos orogenitais, inserção de objetos ou penetração vaginal ou retal, quando a vítima é forçada por medo, ameaças ou violência física. Muitas vezes, a criança ou o adolescente é intoxicado com medicamentos psicoativos, anestésicos, drogas ou 
bebidas alcoólicas, e pode ficar semiconsciente ou em estado de estupor, ocorrendo dissociações psicoativas e desintegradoras, com traumas agudos, que poderão se tornar sintomas crônicos de problemas clínicos, com dificuldades de adaptação psicossocial[24].

De acordo com Bringiotti[25], os indivíduos que sofreram quaisquer tipos de violência na infância ou não foi uma criança aceita, reconhecida ou desejada, terá consequências psicológicas apresentadas durante o seu desenvolvimento, e, principalmente, na forma como irá tratar seus filhos, havendo fatores e recursos de proteção que conseguem remediar estes acontecimentos.

A Constituição Federal[26], em seu artigo 227 parágrafo 4º̣, expõe que a lei punirá severamente o abuso, violência e a exploração sexual da criança e do adolescente, este foi regulamentado pela lei 8.069 de 1990 através do Estatuto da Criança e do Adolescente, demonstrando os direitos fundamentais destas.

Nucci[27] afirma que há números muito baixos de abusos sexuais que são denunciados, e as políticas públicas não dispõe de métodos adequados para 0 registro de estatísticas dos problemas, dificultando a produção de um diagnóstico exato sobre a violência doméstica e sexual no Brasil. O número real de casos é muito maior do que a quantidade de casos denunciados a polícia e ao poder judiciário, estudos do Departamento de Medicina Legal da Unicamp, em 1997, demonstram que só entre $10 \%$ e $20 \%$ das vítimas fazem uma real denúncia do ocorrido.

Desta forma, crianças e adolescentes deixaram de ser tratados como objetos passivos de proteção, como era previsto anteriormente, onde toda a família, sociedade e Estado teriam a obrigação de Ihes protegerem, mas estes não estavam de maneira ativa em relação a legislação, e, tornaram-se objetos de direitos, onde tal processo protetivo ocorre tanto por parte do Estado, internamente, quanto internacionalmente pelas Organizações das Nações Unidas (ONU). Então, o Código Penal brasileiro, artigo 217-A, dispõe sobre ter conjunção carnal ou praticar atos libidinosos com 
crianças menores de 14 anos, instituindo a proteção destas e a punição que será recebida por estes atos.

Sendo crime hediondo através da lei 8.072 de 1990, já o Decreto-lei 2.848[28] de 1940 , demonstra no artigo 213, em seu caput, que pratica estupro quem constranger alguém, mediante violência ou ameaça grave, a ter conjunção carnal ou a permitir que com ele se tenha outro ato libidinoso, onde Furniss[29] separa a mentira destes atos da negação:

Permanece um segredo de família, até mesmo depois de uma clara revelação, e inclusive quando as ameaças legais e estatutárias $h$ á muito tempo já foram removidas; este é o resultado da negação, não da mentira; a mentira relaciona-se ao conceito legal de prova, a negação pertence ao conceito psicológico de crença e assunção da autoria.

De acordo com Azambuja (2011), esta inexistência de uma cultura de denúncia de tais acontecimentos, fragiliza as vítimas de modo que estes continuam sem realizar qualquer mudança diante do agressor, contribuindo para a continuidade de tais episódios. A vulnerabilidade traduz a aptidão psicológica para compreender 0 ato sexual ou as condições para manifestar o desejo pela prática do mesmo, assim, indivíduos com menos de quatorze anos são considerados incapazes de compreender o ato sexual, desta forma, o abuso é cometido mesmo com a expressão, por parte da vítima, do consentimento. Assim, indivíduos com deficiência, sejam elas psicológicas ou físicas, também se enquadram.

Assis[30] demonstra que esta violência ocorrida por pessoas que a criança espera amor, respeito e compreensão é um grande fator de risco que compromete o desenvolvimento da autoestima, competência social e da capacidade de estabelecer relações interpessoais, potencializando a fixação de um autoconceito negativo e uma visão pessimista do mundo.

Havendo o Projeto de Lei pelo Senado, número 253, de 2004, tratando sobre a exploração sexual da criança e do adolescente, através da lei 12.015 de 2009, assim, 
esta não exige que estes casos ocorram mediante violência ou grave ameaça, traçando como uma objetividade fática. Deste modo, o artigo 5ํำ do Estatuto da Criança e do Adolescente impõe que nenhum destes será objeto de qualquer forma de negligência, discriminação, exploração, violência, crueldade e opressão, punindo qualquer atentado que remeta a estas questões seja por ação ou omissão.

Há um despreparo na área da Educação, Saúde e Direito, se unindo com o fato de que a maioria das vítimas e agressores não procuram ajuda nos serviços de saúde e segurança, dificultando a adoção de providências, tornando as redes sociais e os vínculos com os vizinhos uma maneira de proteção para as crianças, tanto as que estão expostas aos vários fatores de risco, como a pobreza, o uso de álcool e drogas, violência e baixa escolarização, como as que desfrutam de um nível menos intenso de dificuldades sociais.

\section{METODOLOGIA}

A presente pesquisa atuou de maneira qualitativa que vem com base bibliográfica, como demonstra Fonseca:

A pesquisa bibliográfica é feita a partir do levantamento de referências teóricas já analisadas, e publicadas por meios escritos e eletrônicos, como livros, artigos científicos, páginas de web sites. Qualquer trabalho científico inicia-se com uma pesquisa bibliográfica, que permite ao pesquisador conhecer o que já se estudou sobre o assunto. Existem, porém, pesquisas científicas que se baseiam unicamente na pesquisa bibliográfica, procurando referências teóricas publicadas com o objetivo de recolher informações ou conhecimentos prévios sobre o problema a respeito do qual se procura a resposta[31].

De acordo com Goldemberg[32], dentro da pesquisa qualitativa os pesquisadores opõem-se ao pressuposto daqueles que defendem uma maneira única de pesquisa, para todas as ciências, levando em consideração que as ciências sociais possuem certa especificidade, necessitando de uma metodologia própria. Assim, estes não 
podem permitir que sua subjetividade torne-se um empecilho para a pesquisa, especialmente, em relação aos seus preconceitos e crenças.

Deste modo, a pesquisa qualitativa utiliza de uma metodologia mais aprofundada, visando traçar as motivações e as resoluções de certas questões a partir da convivência, evitando os métodos que apenas usam de pesquisas matemáticas que realizam estatísticas sobre estes seguimentos. Neste contexto, autores atuais a respeito do tema em questão, são utilizados para fundamentar esta pesquisa, levando em consideração seu conhecimento, pesquisa e opinião sobre.

\section{CONSIDERAÇÕES FINAIS}

Diante de todo o exposto, com o cumprimento dos objetivos propostos, entende-se que a violência intrafamiliar e o abuso de vulneráveis são questões que remetem a cultura social, onde na antiguidade haveria um descaso e até mesmo uma benção quanto a estes atos por parte de outros indivíduos, e estas ideologias foram repassados hereditariamente de modo que a atualidade ainda seja marcada por este descaso em relação a mulheres, idosos e crianças.

Há uma gama de leis e artigos presentes nos códigos brasileiros e na Constituição Federal que visam punir estes casos, entretanto, ainda há uma falta de eficácia em relação a estes, os quais não conseguem atuar quanto a descoberta destes e a prevenção, que seria a melhor imposição. Assim, as denúncias são dificultadas pelas dependências das vítimas pelos agressores, do mesmo modo em que as evidências se tornam difíceis de serem configuradas.

Portanto, é de suma relevância que novas formas de prevenção sejam instauradas, visto que estas são as maneiras mais eficazes de proteger os vulneráveis, onde políticas públicas sociais podem ser criadas em parceria com outras instituições que consigam identificar de maneira mais fácil estes casos. Neste sentido, uma futura pesquisa em relação as maneiras preventivas, é fundamental para o entendimento de sintomas, contexto e das características familiares que levam estes atos a ocorrer. 


\section{REFERÊNCIAS}

ABRAPIA - ASSOCIAÇÃO BRASILEIRA MULTIPROFISSIONAL DE PROTEÇÃO A INFANCIA E À ADOLESCENCIA. Abuso Sexual Contra Criança e adolescentes. $3^{\circ}$ ed. Petrópolis, RJ. Autores e Agentes e Associados. 2002, p. 49.

ASSIS, Simone G. de. Crianças e adolescentes violentados: passado, presente e perspectivas para o futuro. Cadernos de Saúde Pública, Rio de Janeiro, v. 10, supl. ํo 1, 2004.

AZAMBUJA, Maria Regina Fay de. Inquirição da criança vítima de violência sexual: proteção ou violação de direitos? Porto Alegre: Livraria do Advogado 2011.

AZEVEDO, Maria Amélia; GUERRA, Viviane Nogueira de Azevedo, (Org.). Crianças vitímizadas: a síndrome do pequeno poder. 2. ed. São Paulo: Iglu, 2000.

AZEVEDO, Maria Amélia. Contribuições brasileiras à prevenção da violência doméstica contra crianças e adolescentes. In: Westphal MF, organizador. Violência e criança. São Paulo (SP): Editora da Universidade de São Paulo; 2002. p. 125-35.

AZEVEDO, Maria Amélia; GUERRA, Viviane Nogueira de Azevedo. Infância e violência doméstica: fronteiras do conhecimento. São Paulo: Cortez, 2005.

BRASIL. Constituição da República Federativa do Brasil. 1988. Brasília/DF: Senado Federal, $1988 . \quad$ Disponível em: <http://www.planalto.gov.br/ccivil_03/Constituicao/Constituicao.htm>. Acesso em: 18 nov. 2019.

BRASIL. Decreto-Lei no 2.848, de 07 de dezembro de 1940. Código Penal. Disponível em: <http://www.planalto.gov.br/ccivil_03/decretolei/del2848compilado.htm>. Acesso em: 25 nov. 2019. 
BRINGIOTTI, Maria Inés. Lasfamiliasen "situación de riesgo": enlos casos de violencia familiar y maltrato infantil. Texto Contexto Enferm. 2005 Nov; 14(Esp):7885.

CHAUÍ, Marilena. Participando do debate sobre mulher e violência. Perspectivas antropológicas da mulher. Rio de Janeiro, n. 4, 1985, p. 23-62.

COHEN, C.; GOBBETTI, G. J. Abuso sexual intrafamiliar. Revista Brasileira de Ciências Criminais, 2000.

DINIZ, Maria Berenice. Incesto e Alienação Parental. Ed. 2. São Paulo, 2010.

EISENSTEIN, Evelyn. Quebrando o silêncio sobre o abuso sexual. Vol. 1, nº 3 set. 2004.

FONSECA, J. J. S. Metodologia da pesquisa científica. Fortaleza: UEC, 2002. Apostila.

FURNISS, Tilman. Abuso sexual da criança: uma abordagem multidisciplinar manejo, terapia e intervenção legal integrados. Traduzido por Maria Adrian Veríssimo Veronese. Porto Alegre: Artes Médicas, 1993

GOLDENBERG, Mirian. A arte de pesquisar: como fazer pesquisa qualitativa em Ciências Sociais. 8ª ed. - Rio de Janeiro: Record, 2004.

GUERRA, Viviane Nogueira de Azevedo. Violência de pais contra filhos: tragédia revisitada. 3. Ed. São Paulo: Cortez, 1998.

GUERRA, Viviane Nogueira de Azevedo. Violência de pais contra filhos: a tragédia revisitada. 4 ed. - Revistada e ampliada. São Paulo Cortez, 2001.

ISHIDA, Válter Kenji. Estatuto da criança e do adolescente: doutrina e jurisprudência. 16. ed. - São Paulo: Atlas, 2015. 
MINAYO, Maria Cecília de Souza. A difícil e lenta entrada da violência na agenda do setor saúde. Cadernos de Saúde Pública, v. 20, n. 3, p. 646-647, 2004.

NUCCl, Guilherme de Souza. Código de Processo Penal comentado. 4. Ed. São Paulo: Revista dos Tribunais, 2009.

PFEIFFER, Luci; SALVAGNI, Edila P. Visão atual do o abuso sexual na infância e adolescência. Jornal de Pediatria, 81 (supl.5), 2005.

PINTO JUNIOR, A. A.; CASSEPP-BORGES, V.; SANTOS, J. G. Caracterização da violência doméstica contra crianças $e$ adolescentes $e$ as estratégias interventivas em um município do Estado do Rio de Janeiro, Brasil. Cadernos de Saúde Coletiva, v. 23, n. 2, p. 124-131, 2015.

RANGEL, Patrícia Calmon. Abuso sexual: intrafamiliar recorrente. $2^{\underline{a}}$ ed. rev. atual. Curitiba: Juruá Editora, 2011.

RIBEIRO, M. A.; FERRIANI, M. G. C.; REIS, J. N. Violência sexual contra crianças e adolescentes: características relativas à vitimização nas relações familiares. Cad Saúde Pública, 2004.

SANTOS, Adriana Carvalho dos; SANTOS, Maria Lisiane de Moraes dos; NASCIMENTO, Débora Dupas G. Violência Intrafamiliar: caminhos para o enfrentamento na saúde pública. Saúde em Redes, v. 1 n. 2, 2015. Disponível em: http://dx.doi.org/10.18310\%2F2446-4813.2015v1n2p21-30 Acessado em 17 de Março de 2019.

\section{APÊNDICE - REFERÊNCIAS DE NOTA DE RODAPÉ}

3. FONSECA, Franciele Fagundes et al. As vulnerabilidades na infância e adolescência e as políticas públicas brasileiras de intervenção. Revista Paulista de Pediatria, v. 31, n. 2, p. 258-264, 2013. 
4. GUERRA, Viviane Nogueira de Azevedo. Violência de pais contra filhos: tragédia revisitada. 3. Ed. São Paulo: Cortez, 1998, p. 262.

5. BRASIL. Constituição da República Federativa do Brasil. 1988. Brasília/DF: Senado Federal, 1988.

Disponível em: <http://www.planalto.gov.br/ccivil_03/Constituicao/Constituicao.htm>. Acesso em: 18 nov. 2019.

6. ABRAPIA - ASSOCIAÇÃO BRASILEIRA MULTIPROFISSIONAL DE PROTEÇÃO A INFANCIA E À ADOLESCENCIA. Abuso Sexual Contra Criança e adolescentes. $3^{\circ}$ ed. Petrópolis, RJ. Autores e Agentes e Associados. 2002, p. 49.

7. AZEVEDO, M. A. Contribuições brasileiras à prevenção da violência doméstica contra crianças e adolescentes. In: Westphal MF, organizador. Violência e criança. São Paulo (SP): Editora da Universidade de São Paulo; 2002.

8. RIBEIRO, M. A.; FERRIANI, M. G. C.; REIS, J. N. Violência sexual contra crianças e adolescentes: características relativas à vitimização nas relações familiares. Cad Saúde Pública, 2004.

9. EISENSTEIN, Evelyn. Quebrando o silêncio sobre o abuso sexual. Vol. 1, no 3 set. 2004 , p. 26

10. MINAYO, Maria Cecília de Souza. A difícil e lenta entrada da violência na agenda do setor saúde. Cadernos de Saúde Pública, v. 20, n. 3, p. 646-647, 2004.

11. AZEVEDO, Maria Amélia; GUERRA, Viviane Nogueira de Azevedo, (Org.). Crianças vitímizadas: a síndrome do pequeno poder. 2. ed. São Paulo: Iglu, 2000.

12. SANTOS, Adriana Carvalho dos; SANTOS, Maria Lisiane de Moraes dos; NASCIMENTO, Débora Dupas G. Violência Intrafamiliar: caminhos para o enfrentamento na saúde pública. Saúde em Redes, v. 1 n. 2, 2015. Disponível em: http://dx.doi.org/10.18310\%2F2446-4813.2015v1n2p21-30 Acessado em 17 de março de 2019. 
13. AZAMBUJA, Maria Regina Fay de. Inquirição da criança vítima de violência sexual: proteção ou violação de direitos?. Porto Alegre: Livraria do Advogado, 2011, p. 65.

14. ISHIDA, Válter Kenji. Estatuto da criança e do adolescente: doutrina e jurisprudência. 16. ed. - São Paulo: Atlas, 2015, p. 12.

15. GUERRA, Viviane Nogueira de Azevedo. Violência de pais contra filhos: a tragédia revisitada. 4 ed. - Revistada e ampliada. São Paulo Cortez, 2001.

16. RANGEL, Patrícia Calmon. Abuso sexual: intrafamiliar recorrente. $2^{\underline{a}}$ ed. rev. atual. Curitiba: Juruá Editora, 2011, p. 29.

17. DINIZ, Maria Berenice. Incesto e Alienação Parental. Ed. 2. São Paulo, 2010, p. 243-244.

18. COHEN, C.; GOBBETTI, G. J. Abuso sexual intrafamiliar. Revista Brasileira de Ciências Criminais, 2000.

19. CHAUÍ, Marilena. Participando do debate sobre mulher e violência. Perspectivas antropológicas da mulher. Rio de Janeiro, n. 4, 1985, p. 23-62.

20. AZEVEdo, Maria Amélia; GUERRA, Viviane Nogueira de Azevedo, (Org.). Crianças vitímizadas: a síndrome do pequeno poder. 2. ed. São Paulo: Iglu, 2000, p. 35.

21. FURNISS, Tilman. Abuso sexual da criança: uma abordagem multidisciplinar manejo, terapia e intervenção legal integrados. Traduzido por Maria Adrian Veríssimo Veronese. Porto Alegre: Artes Médicas, 1993.

22. PFEIFFER, Luci; SALVAGNI, Edila P. Visão atual do o abuso sexual na infância e adolescência. Jornal de Pediatria, 81 (supl.5), 2005, p. 199.

23. PINTO JUNIOR, A. A.; CASSEPP-BORGES, V.; SANTOS, J. G. Caracterização da violência doméstica contra crianças e adolescentes e as estratégias interventivas 
em um município do Estado do Rio de Janeiro, Brasil. Cadernos de Saúde Coletiva, v. 23, n. 2, p. 124-131, 2015.

24. EISENSTEIN, Evelyn. Quebrando o silêncio sobre o abuso sexual. v. 1, no 3 set. 2004, p. 26.

25. BRINGIOTTI, María Inés. Las familias en "situación de riesgo" en los casos de violencia familiar y maltrato infantil. Texto contexto - enferm. [online]. vol.14, 2005.

26. BRASIL. Constituição da República Federativa do Brasil. 1988. Brasília/DF: Senado Federal, $1988 . \quad$ Disponível em: <http://www.planalto.gov.br/ccivil_03/Constituicao/Constituicao.htm>. Acesso em: 18 nov. 2019.

27. NUCCI, Guilherme de Souza. Código de Processo Penal comentado. 4. Ed. São Paulo: Revista dos Tribunais, 2009.

28. BRASIL. Decreto-Lei no 2.848, de 07 de dezembro de 1940. Código Penal. Disponível em: <http://www.planalto.gov.br/ccivil_03/decretolei/del2848compilado.htm>. Acesso em: 25 nov. 2019.

29. FURNISS, Tilman. Abuso sexual da criança: uma abordagem multidisciplinar manejo, terapia e intervenção legal integrados. Traduzido por Maria Adrian Veríssimo Veronese. Porto Alegre: Artes Médicas, 1993, p. 31.

30. ASSIS, Simone G. de. Crianças e adolescentes violentados: passado, presente e perspectivas para o futuro. Cadernos de Saúde Pública, Rio de Janeiro, v. 10, supl. no $1,2004$.

31. FONSECA, J. J. S. Metodologia da pesquisa científica. Fortaleza: UEC, 2002, p. 32.

32. GOLDENBERG, Mirian. $A$ arte de pesquisar: como fazer pesquisa qualitativa em Ciências Sociais. 8ª ed. - Rio de Janeiro: Record, 2004. 
Enviado: Fevereiro, 2020.

Aprovado: Março, 2020. 